\title{
Research Paper: Situational Modulation of Emotion Recognition Abilities in Children With Secure and Insecure Attachment: The Role of Gender
}

Leila Mirbagheri' ${ }^{1}$, Ali Khatibi ${ }^{* *}$ (1), Parisa Seyed Mousavi ${ }^{3}$ (1)

1. Department of Family Therapy Psychology, Family Research Institute, Shahid Beheshti University, Tehran, Iran.

2. Centre of Precision Rehabilitation for Spinal Pain, University of Birmingham, Birmingham, Birmingham, United Kingdom of England.

3. Family Research Institute, Shahid Beheshti University, Tehran, Iran.

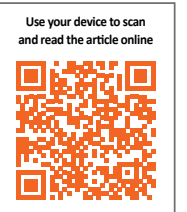

Citration: Mirbagheri, L., Khatibi, A., \& Seyed Mousavi, P. (2020). Situational Modulation of Emotion Recognition Abilities in Children With Secure and Insecure Attachment: The Role of Gender. Journal of Practice in Clinical Psychology, 8(3), 183-192. https://doi.org/10.32598/jpcp.8.3.10.606.1

doi) https://doi.org/10.32598/jpcp.8.3.10.606.1

\section{(i) (\$)}

Article info:

Received: 13 Nov 2020

Accepted: 02 Feb 2020

Available Online: 01 Jul 2020

Keywords:

Emotion recognition, Intensity rating, Attachment, Gender

\section{ABSTRACT}

Objective: Considering the role of attachment in the emotional development of children, the purpose of this study was to test the situational modulation of emotion recognition in children with secure/insecure attachment with regard to gender in Iranian students.

Methods: this casual comparative study was done on a pool of 200 students aged 7-9 years from elementary schools of Tehran, Iran. The participants completed the Middle Childhood Attachment Scale (MCSA), of whom 60 children were assigned to two groups based on their scores on MCAS (secure vs. insecure). They read stories developed to manipulate the attachment schema, and after each story, they were tested for emotion recognition abilities (classification and intensity rating). Happy, sad, angry, and fearful faces were presented and reaction time was recorded using the AFFECT4.0 software.

Results: All children irrespective of attachment style, were faster in the identification of others' emotional expressions in attachment situations than in a neutral situation. Boys made more errors in attachment situations than in the neutral situation, while for girls it did not differ. Among children with secure attachment, boys were faster than girls in recognition of emotion.

Conclusion: In terms of attachment theory, attachment styles could have an important impact on the development process of the child's emotional skills.

\section{* Corresponding Author:}

Ali Khatibi, PhD.

Address: Centre of Precision Rehabilitation for Spinal Pain, University of Birmingham, Birmingham, Birmingham, United Kingdom of England

Tel: +44 (121) 4144133

E-mail: ali.khatibi@gmail.com 


\section{Highlights}

- The attachment style of children may influence their emotional recognition ability.

- Context can interact with the attachment style and influence emotion recognition.

- We showed that gender influences the interaction between attachment style and the context.

\section{Plain Language Summary}

Emotion recognition is an ability that is directly linked to the social development of children. Previous researchers suggested that emotion recognition can be influenced by attachment style and context. However, no research has investigated the interaction between them. In our study, we showed that gender plays a factor in this interaction. Boys make more errors in attachment situations than in neutral situations, while girls demonstrate no difference in these situations. Our findings suggest that future studies take a closer look at the role of gender factors in investing the interaction between attachment, context, and emotion recognition.

\section{Introduction}

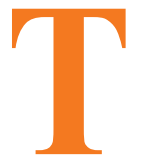

he relationship between children and their parents is especially important in shaping their emotional life (Cassidy \& Shaver, 2008). According to Bowlby (1980), early attachment-related experiences may influence a person's processing style and interpretation of emotional information and how he/she regulates negative emotions during interactions. The internal working model reflects the regulating function of the attachment strategies that shape a person's expectation about the interaction with caregivers (Shaver \& Mikulincer, 2002). A secure attachment between the infant and the primary caregiver is an essential element in the primary caring environment and is the basis for subsequent socio-emotional development. Secure attachments seem to have a wide range of growth benefits over insecure ones, such as better peer relationships (Schneider, Atkinson \& Tardif, 2001), reduced behavioral problems (Fearon, Bakermans-Kranenburg, van IJzendoorn, Lapsley \& Roisman, 2010), and reduced affective disorders (Murray et al., 2011).

Niedenthal, Brauer, Robin, and Innes-Ker, (2002) showed that people with different attachment styles differ in discriminating emotions (Niedenthal, Brauer, Robin, and Innes-Ker). The caregiver's emotional facial expression is one of the most important factors in emotional learning in childhood (Tomkins, 1991). Besides, de Montis et al. (2013) reported problems in the accurate decoding of others' facial expressions among people with insecure attachment. The impact of emotional attachment on understanding and judgment abilities in mid-childhood has been reported (Pons, Harris, \& de Rosnay, 2004). Studies have suggested that early attachment style, and accordingly the internal working model can predict a child's ability in the interpretation of emotions in faces (Steele, Steele \& Croft, 2008).

Middle-childhood (ages 6-12 years) is proposed as a critical stage in the development of emotional competence. During this period, high-level regulatory strategies, including those involved in the cognitive re-evaluation of some features of a face (like the eyes and the mouth) in recognizing facial expressions show quick progress (Pons et al., 2004). Some studies provided evidence in support of the possible effect of the attachment style in middle-childhood on children's' ability to understand and judge the emotional expression of others (Pons et al., 2004). Therefore, accurate decoding of facial expressions increases the child's chance for a better understanding of his social environment and is vital for proper functioning in social interactions (Karayanidis, Kelly, Chapman, Mayes \& Johnston, 2009). Zimmerman (2006) proposed that deficits in emotion recognition partly explain why children with insecure attachments are more aggressive than secure ones.

Situational determinants may have different influences on children with secure and insecure attachment styles. A secure child's emotional reaction to a stressful situation can be different from an insecure child, and this might influence their abilities in communicating with others and receiving adequate support. While some studies have examined the relationship between children's understanding of emotional expressions and their attachment style (Ontai \& Thompson, 2002), no study (so far and to the 
best of our knowledge) has investigated situational modulation of emotion recognition abilities among children with different attachment styles. On the other hand, it has been suggested that there are differences in the demonstration of different attachment styles in girls and boys.

Turner (1991) found that insecure boys showed more aggressive, disruptive, assertive, controlling, and attention-seeking behavior than secure boys. Insecure girls showed more dependent behavior than secure children but less assertive and controlling behavior, and more positive expressive behavior and compliance. In this study, we tried to investigate the effect of perceived stress in a situation on children with different attachment styles' abilities in recognition of others' emotional expression by taking gender differences into account. In addition, examining the effect of attachment styles on different aspects of the cognitive-behavioral system, especially the recognition of emotions in children is useful for both schools and families. The results of the present study could be valuable for family therapists and other mental health practitioners. Also, it will help reduce behavioral problems and increase the quality of the close relationship between parents and children.

\section{Methods}

\section{Participants}

In this casual comparative study, the target population was all girl and boy students in Tehran elementary schools. Participants were selected from a pool of 200 children aged 7-9 years. All participants completed the Middle Childhood Attachment Scale (MCSA). Sixty children (33 females) were selected to take part in the experiment. Individual scores were normalized between -4 and 4 . The selection was based on their score in the MCAS (two groups: secure $(n=30$, scored between 1 and 4 ; mean age: 8.43 years) and insecure $(n=30$, scored between -1 and -4 ; mean age: 8.5 years children). Before the data collection, a letter was sent to the parents with information about the purpose and the methodology of the study. A copy of the Child Behavior Checklist (CBCL) was also sent to the parents to check for exclusion criteria, which involved psychological disorders, such as Attention Deficit Hyperactivity Disorder (ADHD), autism, depression, and anxiety-related problems. Written informed consent was obtained from the parents and active informed consent was obtained from the children. The ethical committee of Shahid Beheshti University reviewed and approved the protocol of this study.
Measures

\section{Middle Childhood Attachment Scale}

Participants completed the MCAS (Ronaghi, Delavar \& Mazaheri, 2012). The MCAS assesses the two central dimensions in the attachment model: attachment anxiety and avoidance. The anxiety scale (14 items) targets feeling of fear of abandonment and strong desires for an inter-personal merger (e.g. "when children are separated from their mother, they are not very worried and upset"). The avoidance scale (14 items) targets discomfort with closeness, dependence, and intimate self-disclosure (e.g. " when children are separated from their mother, they are very worried and upset). Items are rated on a 3-point Likert scale rating from very little to very much. The children were asked to rate the 14 anxiety and 14 avoidance statements about their mother. Their scores were defined on a graph that divided children into four attachment groups (secure, avoidance, anxiety, ambivalent). Both subscales have shown excellent psychometric properties. Test-retest reliability scores for the anxiety and the avoidant components were 0.52 and 0.56 , respectively, and Cronbach's alpha was 0.82, Cronbach's alpha for the MCAS in the current study were 0.57 and 0.62 for anxious and avoidant attachment, respectively (Ronaghi et al., 2012).

\section{Working memory (Wechsler Intelligence Scale for Children-Revised)}

Memory was assessed using the Working Memory subtest (Picture Span \& Letter-Number Sequencing) as the revised version Wechsler Intelligence Scale for Children (WISC-RN) developed by David Wechsler. It is an individually administered intelligence test for children between 6 and 16 years. The average reliability coefficients ranged from 0.77 to $.86(\mathrm{Mdn}=0.80)$ for the verbal scale subtests and from 0.70 to $.85(\mathrm{Mdn}=0.72)$ for the performance scale subtests (Wechsler, 1974).

\section{The child behavior checklist (CBCL)}

CBCL has 113 items that are scored on a 3-point Likert scale ( 0 : Not true, 1: Somewhat or sometimes true, and 2: very true or often true). It has two broadband scales (internalizing and externalizing). Here, ADHD, autism, depression, and anxiety subtests of the CBCL were used (Achenbach, 2001). CBCL for ages 6-18 years has demonstrated good test-retest reliability and good cross-informant correlations among parents for the competence scales, the empirically-based problem scales, and the DSM-Oriented scales (Achenbach, 2001). It has well-documented reliability and validity for assess- 
ing behavioral problems among Iranian samples. Intercorrelations among the scales ranged from 0.50 to .81 $(\mathrm{P}<0.01$ ), internal consistency reliabilities (coefficient alphas) for children ranged from 0.65 to 0.85 , and testretest reliabilities (using the Pearson $r$ ) ranged from 0.32 to 0.67 (Minaei, 2006).

\section{Task description}

\section{Face Stimuli}

Face stimuli used in this study were 48 images of children showing four types of emotional facial expressions (happy, angry, fearful, and sad) and there was an equal number of girls and boys. Images acquired from the Dartmouth database of children's faces and all nonfacial features (i.e., hair, neck, and ears) were covered by a mask with the same color as the background (Dalrymple, Gomez \& Duchaine, 2013).

\section{Task}

The task was programmed using Affect 4.0 (Spruyt, Clarysse, Vansteenwegen, Baeyens \& Hermans, 2010). Each trial started with a fixation cross followed by a facial expression. Along with the expression, four options appeared below the image (Happy, Angry, Fearful, and Sad). The subject had to click the option that corresponded to the emotion in the face. The reaction time and the choice of the subject were recorded. After the subject triggered the response, a VAS appeared on the screen. There were ten grades on the VAS (left anchor: $0=$ no emotion at all, right anchor: $10=$ most intense emotional expression). The subject was asked to click on a point on the scale, which corresponded to the perceived intensity of emotion in the expression in that trial. After the subject clicked the scale, the screen was cleared and after 1000-1500 ms the next trial started. Subjects had no time limitation for doing the task. Images and scales remained on the screen until the response was triggered. Participants did not get any feedback during the task.

\section{Activation of the Attachment system}

The purpose of this manipulation was to create attachment and neutral situations to later evaluate its effect on children's ability to face recognition. To do so, we used a scenario, in which a boy or a girl (of the same gender and age) played the key role. The subject of the story misses the school bus on his way back from a picnic and starts to get worried about the consequences (e.g. losing parents). The story had two parts and stayed unfinished before asking the subject to complete the second emotion evaluation task.
The scenario was inspired by the stories developed by MacArthur Story Stem Battery (Emde, Wolf \& Oppenheim, 2003). Mac Arthur's stories were designed to elicit children's narrative, and it is believed that attachment activation happens during the story completion. The first version of our story was piloted in a sample of 27 children (7-9 years), and attachment was assessed before and after that. Based on the outcome of the pilot and feedback from subjects, minor changes were applied to the story, and another pilot was run on children (7-9 years) to test the effectiveness of the story in the activation of the attachment system. The story ending was positive (the lost kid found his family and reunited with them).

\section{Procedure}

The inclusion criterion was children aged 7-9 years with attachment style. Exclusion criteria were psychological disorders, such as ADHD, autism, depression, and anxiety-related problems, and cognition impairment in memory and attention tasks, and the subjects with the visual disorder were tested individually in a testing room designated for this study. After receiving written consent from the parents, the subject received information about the study, and personal consent was acquired from the child. They then completed the MCAS, and the Wechsler Intelligence Scale was administered. Then, they moved to another desk where they sat in front of a computer screen placed $40 \mathrm{~cm}$ away from the tip of their nose. They received detailed information and examples about the task and how they should complete the emotion recognition and intensity rating tasks. Next, the experimenter (L.M.) read the unfinished story and afterward asked the subject to perform the emotion recognition and intensity rating task for the second time. The time for completing the experiment was about $50 \mathrm{~min}$. After the completion of the second task, the rest of the story (happy ending) was read to the subject, then they were thanked, debriefed, and received their compensation (a toy).

\section{Data preparation and analysis plan}

The data of three parameters were extracted from Affect 4. The number of errors in face recognition for each emotion was transformed into percentages and the response time that indicates the time spent to select the emotion of each face and the intensity rating of each emotion were recorded. Analyses were conducted using SPSS 18.0. To examine differences between two groups in demographic characteristics, $\mathrm{X}^{2}$ and t-tests were used for categorical and continuous variables, respectively. 

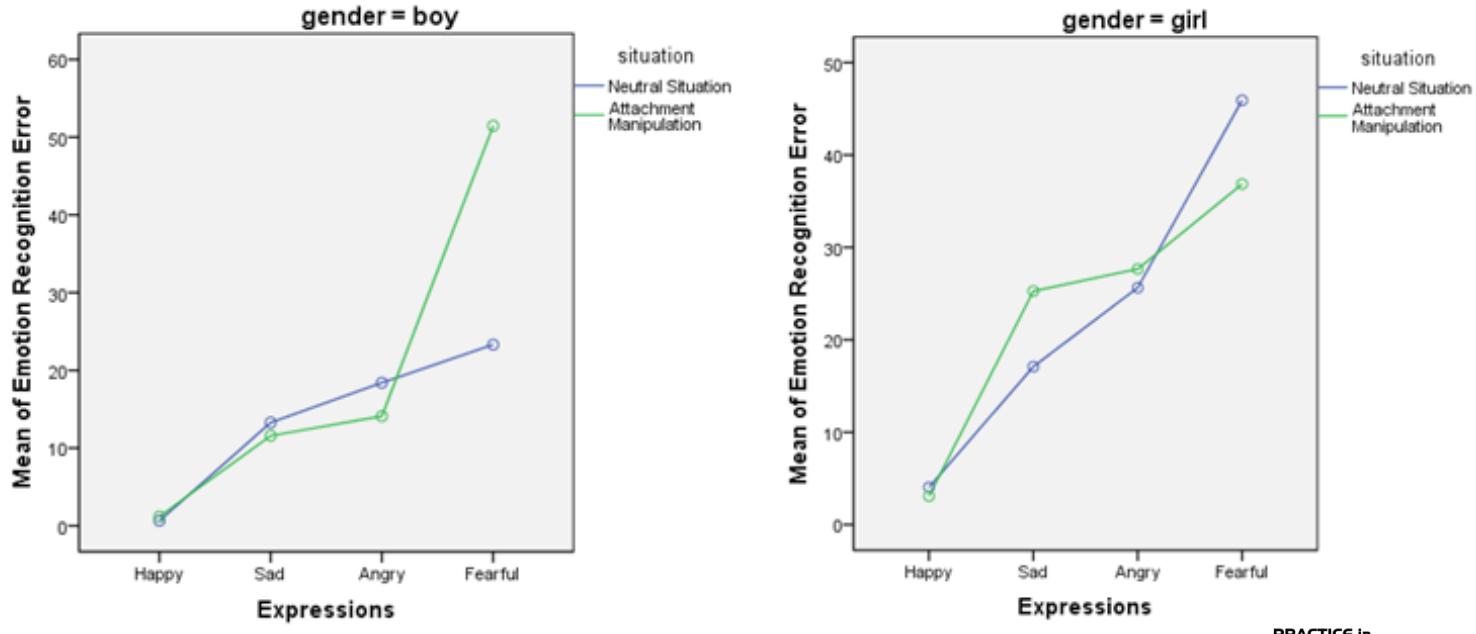

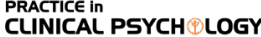

Figure 1. Mean percentage of emotion recognition errors separately for boys and girls (each graph present the interaction between expression, error rate, and situation)

Three independent repeated measures ANOVA tests were run on emotion recognition error, emotion intensity rating, and the response time. Type of expression (4 levels: happy, sad, angry, fearful) and the situation ( 2 levels: neutral situation vs. attachment manipulation situation) were included as the within-subjects factors. The group of the subject (2 levels: secure vs. insecure) and gender ( 2 levels: boy vs. girl) were included as the between-subjects factors. Where a significant difference was obtained in ANOVA tests, relevant t-tests were used to clarify these effect (s) further.

The significant level for these analyses was set at $\alpha=5 \%$. Where the sphericity assumption was not met, the

Table 1. Mean \pm SD of study variables for each emotion in two different situations and attachment groups

\begin{tabular}{|c|c|c|c|c|c|}
\hline \multirow{3}{*}{ Variables } & \multirow{3}{*}{ Emotions } & \multicolumn{4}{|c|}{ Mean $\pm S D$} \\
\hline & & \multicolumn{2}{|c|}{ Secure Attachment } & \multicolumn{2}{|c|}{ Insecure Attachment } \\
\hline & & Neutral Situation & Situation & Neutral Situation & Situation \\
\hline \multirow{4}{*}{ 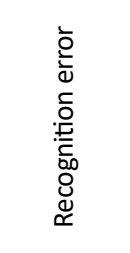 } & Happy & $2.78 \pm 8.84$ & $0.55 \pm 3.04$ & $2.22 \pm 5.76$ & $3.89 \pm 13.62$ \\
\hline & Sad & $13.33 \pm 24.52$ & $17.22 \pm 26.43$ & $17.78 \pm 21.41$ & $21.11 \pm 22.29$ \\
\hline & Angry & $23.33 \pm 26.11$ & $22.78 \pm 29.52$ & $21.67 \pm 19.15$ & $20.55 \pm 23.44$ \\
\hline & Fearful & $35 \pm 30.12$ & $38.89 \pm 28.81$ & $36.67 \pm 33.16$ & $48.33 \pm 32.26$ \\
\hline \multirow{4}{*}{ 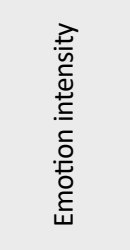 } & Happy & $4.01 \pm 1.19$ & $3.99 \pm 1.02$ & $4.09 \pm 0.78$ & $3.8 \pm 0.99$ \\
\hline & Sad & $3.56 \pm 0.1$ & $3.38 \pm 1.14$ & $3.72 \pm 1.02$ & $3.34 \pm 0.94$ \\
\hline & Angry & $4.01 \pm 0.95$ & $3.82 \pm 0.92$ & $3.7 \pm 1.06$ & $3.8 \pm 1.07$ \\
\hline & Fearful & $3.79 \pm 0.98$ & $3.42 \pm 0.92$ & $3.87 \pm 1.14$ & $3.64 \pm 0.97$ \\
\hline \multirow{4}{*}{ 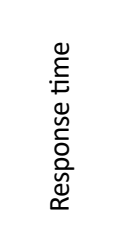 } & Happy & $3.08 \pm 1.17$ & $2.02 \pm 0.47$ & $2.89 \pm 1.12$ & $2.24 \pm 0.53$ \\
\hline & Sad & $3.7 \pm 1.16$ & $3.42 \pm 1.01$ & $4.26 \pm 1.49$ & $3.27 \pm 1.2$ \\
\hline & Angry & $3.62 \pm 1.17$ & $3.04 \pm 0.95$ & $3.51 \pm 0.92$ & $2.92 \pm 1.05$ \\
\hline & Fearful & $4.82 \pm 1.75$ & $3.45 \pm 0.9$ & $4.12 \pm 1.32$ & $3.47 \pm 1.04$ \\
\hline
\end{tabular}


Greenhouse-Geisser correction was applied. To quantify the effect size for the ANOVA and t-tests, partial etasquared $\eta^{2} p$ and Cohen's d were calculated, respectively.

\section{Results}

There were no significant differences between children with secure and insecure attachment in terms of age $\left[\mathrm{t}_{(58)}=0.43\right.$, $\mathrm{P}=0.66]$ and gender $\left[\chi^{2}(1, \mathrm{~N}=60)=0.06, \mathrm{P}=0.79\right]$.

A group (2 levels: secure vs. Insecure $) \times$ gender ( 2 levels: boy vs. girl $) \times$ situations ( 2 levels: before attachment manipulation and after) $\times$ expressions (4 levels: Happy, angry, sad, fearful) repeated measures ANOVA was conducted for each extracted parameter separately (Figure 1). The Mean \pm SD of these parameters are presented in Table 1 .

The ANOVA results for emotion recognition error showed a significant main effect for situation $\left[\mathrm{F}_{(1,}\right.$ $\left.{ }_{56)}=4.09, \mathrm{P}<0.048, \eta^{2} \mathrm{p}=0.07\right]$. The main effect of expression was also significant $\left[\mathrm{F}_{(2.56,143.57)}=44.54, \mathrm{P}<0.001\right.$ $\left.\eta^{2} p=0.44\right]$. These main effects were qualified by a significant interaction between situation and expression $\left[\mathrm{F}_{(2.62}\right.$ $\left.{ }_{146.7)}=2.91, \mathrm{P}=0.04, \eta^{2} \mathrm{p}=0.05\right]$ and also situation, expression, and gender $\left[\mathrm{F}_{(2.62,146.7)}=14.49, \mathrm{P}<0.001 \eta^{2} \mathrm{p}=0.21\right]$. There were no other significant main effects or interactions. In order to understand the significant interactions, paired sample t-tests were performed to compare each emotional expression in both neutral and attachment manipulation situations for each gender separately. The results of paired t-test for boys showed a significant difference between fear recognition errors in two situations $\left[\mathrm{t}_{(26)}=5.66, \mathrm{P}<0.001, \mathrm{~d}=1\right]$, while girls showed significant difference in sad faces in two situations $\left[\mathrm{t}_{(32)}=2.7\right.$, $\mathrm{P}=0.011, \mathrm{~d}=0.47]$.

The results for emotion intensity ratings were largely similar to emotion recognition error (Figure 2). Significant main effects were found for situation $\left[\mathrm{F}_{(1,56)}=7.05\right.$, $\left.\mathrm{P}=0.01, \eta^{2} \mathrm{p}=0.11\right]$ and expression $\left[\mathrm{F}_{(2.42,135.5)}=9.93\right.$, $\left.\mathrm{P}<0.001, \eta^{2} \mathrm{p}=0.15\right]$. The interaction effect of situation, expression, and gender was also significant $\left[\mathrm{F}_{(3,}\right.$ $\left.{ }_{168)}=5.49, \mathrm{P}=0.001, \eta^{2} \mathrm{p}=0.09\right]$. No other significant effects were found. Post hoc t-tests were conducted to clarify significant differences in emotion intensity ratings for different expressions for each gender in two situations. The results indicated that boys rated all four emotions less intense in the attachment manipulation situation; however, only the data of angry faces reached significance $\left[\mathrm{t}_{(26)}=3.78, \mathrm{P}=0.01, \mathrm{~d}=0.73\right]$. The difference between happy faces was also marginally significant $\left[\mathrm{t}_{(26)}=2.06, \mathrm{P}=0.05, \mathrm{~d}=0.4\right]$.
Girls, on the other hand, showed a significant decrease in sad and intensity ratings of fearful expressions in the attachment manipulation situation $\left[\mathrm{Sad}: \mathrm{t}_{(32)}=2.35\right.$, $\mathrm{P}=0.025$, $\mathrm{d}=0.41$; Fearful: $\mathrm{t}_{(32)}=2.12, \mathrm{P}=0.042, \mathrm{~d}=0.37$ ]. The difference between intensity ratings of angry faces was close to significance, but with an increase in intensity ratings in attachment manipulation situation $\left[\mathrm{t}_{(32)}=2.01, \mathrm{P}=0.053, \mathrm{~d}=0.35\right]$.

The analysis for response time (Figure 3 ) showed a significant main effect of situation $\left[\mathrm{F}_{(1,56)}=29.61, \mathrm{P}<0.001\right.$, $\left.\eta^{2} \mathrm{p}=0.35\right]$, and a significant effect of expression $\left[\mathrm{F}_{(3,}\right.$ $\left.{ }_{168)}=55.73, \mathrm{P}<0.001, \eta^{2} \mathrm{p}=0.5\right]$ that were subsumed under a significant situation by expression and group interaction $[\mathrm{F}$ $\left.(3,168)=3.56, P=0.016, \eta^{2} \mathrm{p}=0.06\right]$. There was also a significant interaction between gender and group $\left[\mathrm{F}_{(1,56)}=5.35\right.$, $\left.\mathrm{P}=0.02, \eta^{2} \mathrm{p}=0.08\right]$. No other significant effects were found.

As illustrated in Figure 3, the significant main effect of situation is clear to decrease response time for all expressions in the manipulation situation. To understand the interaction between situation, expression, and group, we compared the response times of each expression in both situations for each group using paired sample t-test. The results of the insecure attachment group showed that the response time in the manipulation situation decreased significantly for all expressions [happy: $\mathrm{t}_{(29)}=2.85$, $\mathrm{P}=0.01, \mathrm{~d}=0.52$; sad: $\mathrm{t}_{(29)}=2.98, \mathrm{P}=0.01, \mathrm{~d}=0.54$; angry: $\left.\mathrm{t}_{(29)}=2.11, \mathrm{P}=0.04, \mathrm{~d}=0.38\right]$, except fearful faces $\left[\mathrm{t}_{(29)}=1.9\right.$, $\mathrm{P}=0.07]$. In the secure attachment group, there was a significant decrease for happy and fearful expressions [happy: $\mathrm{t}_{(29)}=5.01, \mathrm{P}<0.001, \mathrm{~d}=0.91$; fearful: $\mathrm{t}_{(29)}=4.2$, $\mathrm{P}<0.001, \mathrm{~d}=0.76]$, the difference for angry faces was close to significance $\left[\mathrm{t}_{(29)}=2.04, \mathrm{P}=0.051, \mathrm{~d}=0.37\right]$, and the results of sad expressions failed to reach significance $\left[\mathrm{t}_{(29)}=1.05, \mathrm{P}=0.3\right]$.

To clarify the significant interaction between gender and group, independent sample t-tests were performed to compare the overall mean of response time in two attachment groups. Results showed a marginally significant difference between boys (Mean \pm SD: $3.14 \pm 0.42$ ) and girls (Mean \pm SD: $3.6 \pm 0.72)$ in response time in the secure attachment group $\left[\mathrm{t}_{(28)}=2.04, \mathrm{P}=0.051, \mathrm{~d}=0.77\right]$, while there was no significant difference between boys (Mean \pm SD: $3.45 \pm 0.49$ ) and girls (Mean \pm SD: $3.23 \pm 0.52$ ) in the insecure attachment group $\left[\mathrm{t}_{(28)}=1.16, \mathrm{P}=0.25\right]$.

\section{Discussion}

The current study was done to investigate the situational modulation of emotion recognition abilities in children with secure and insecure attachment by taking gender dif- 

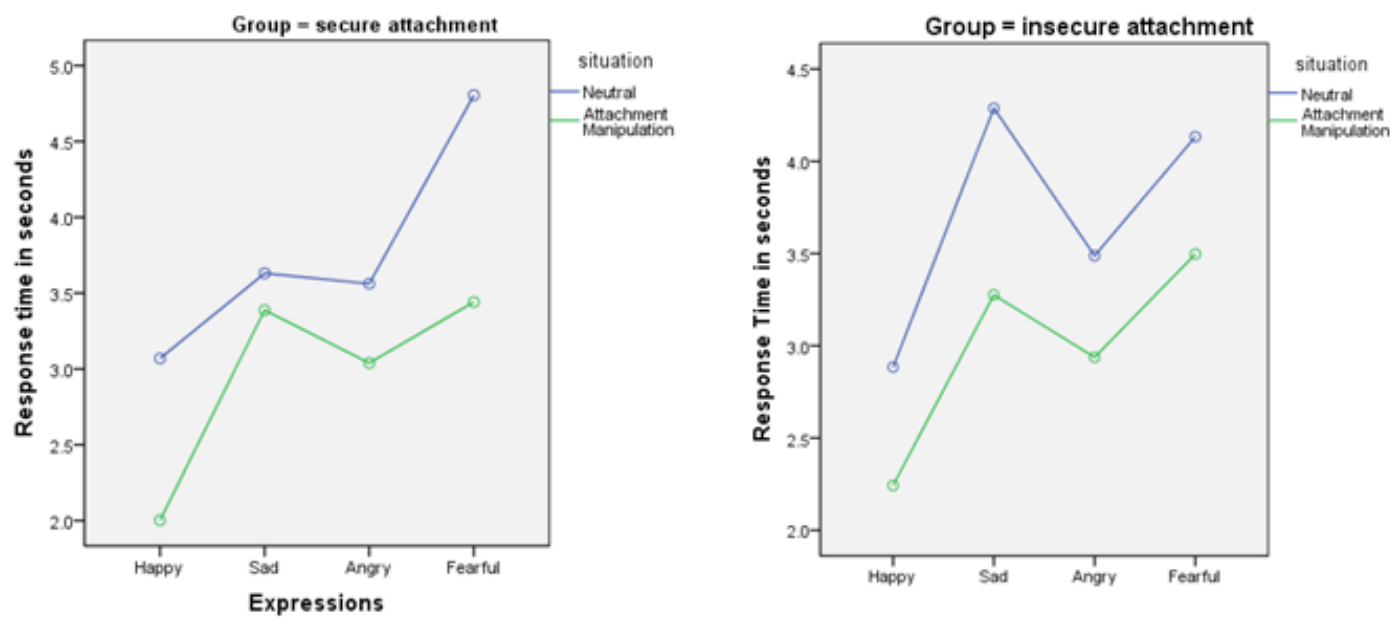

PRACTICE In
CLINICAL PSYCH LOGY

Figure 2. Mean emotion intensity ratings separately for boys and girls (each graph presents the interaction between expression, emotion rating, and situation)

ferences into account. The results indicated that children with secure and insecure attachment in two situations (attachment activated vs. not activated) were different in emotion recognition accuracy and emotion intensity rating. Besides, both secure and insecure children were faster in the identification of others' emotional expressions in attachment situations than in a neutral situation (for fear, the difference showed a trend toward significance). There was also a marginally significant difference between boys' and girls' response time in the secure attachment group. The result is consistent with previous studies suggesting the existence of a connection between attachment style and processing of emotion in others' facial expressions (Dan \& Raz, 2012; Dewitte \& De Houwer, 2008; Fraedrich, Lakatos \& Spangler, 2010; Zimmerman, 2006).

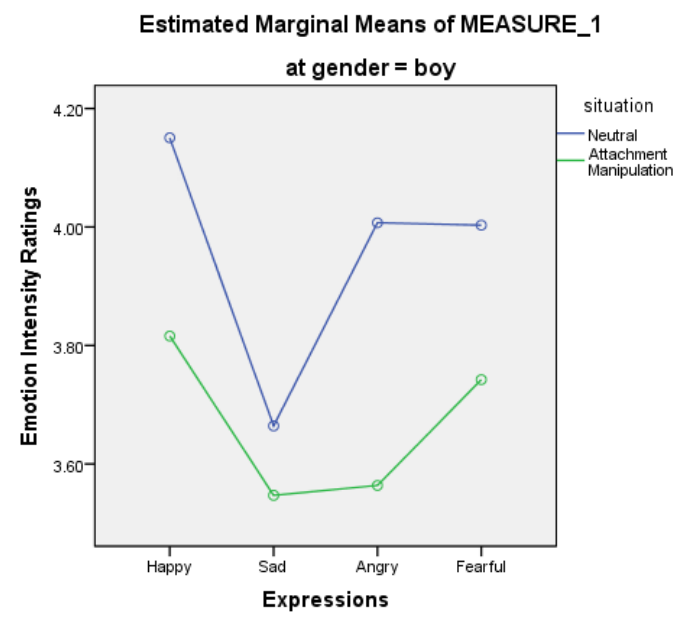

Attachment theory can explain the results of this study about differences in emotion recognition accuracy and emotion intensity rating in two secure and insecure attachments. The attachment theory by Bowlby (1980) postulates that through early experiences with their primary caregiver, individuals develop an Internal Working Model (IWM) of themselves, others, and close relatives. It is assumed that IWMs include emotional and motivational as well as cognitive knowledge or representations about attachment, the importance of attachment, the availability of attachment figures, and about the self as being worthy or unworthy of love. These beliefs influence expectations, perceptions, and behavior in future relationships (Petrowski, Schurig, Schmutzer, Brähler, \& Stöbel-Richter, 2015; Spangler, Maier, Geserick \& von Wahlert, 2010).

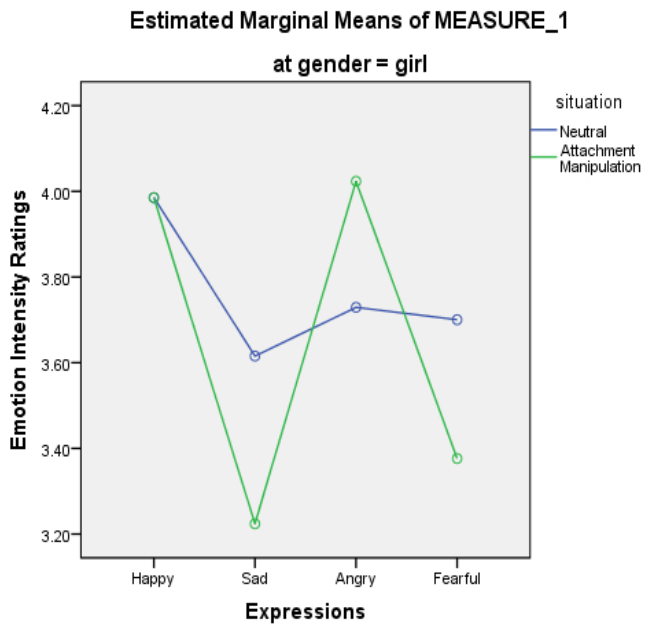

PRACTICE In
CLINICAL PSYCH $\oplus$ LOGY

Figure 3. Mean response times separately for secure and insecure children (each graph presents the interaction between expression, response time, and situation) 
The ability to recognize a caregiver is essential for infants and is linked to their chance of survival. Human infants inherently express a keen interest in faces, and they are able to recognize their mother's face within a few months after birth or even shortly after birth under certain conditions. The bond between the infant and the mother is mostly based on their experience of mutual interaction; the infants thus learn to recognize the emotional state of the mother or other people. (Minagawa-Kawai et al., 2008). The literature suggests that after acquiring the ability to recognize emotions, people with different attachment styles are different in social information processing that may affect their future relationships (Escobar et al., 2013).

The defense exclusion hypothesis states that people with insecure attachments filter out information about their attachment figures because it is related to psychological pain. Even information about positive attachment is considered painful because it creates the impression that they have had only a few positive experiences with their caregiver or no experience at all. This selective processing, described as bias, protects the insecure person from re-experiencing distress in the past and limits activation of the attachment system (Bowlby, 1980; Brenning, Soenens, Braet \& Bosman, 2011). In contrast, it is assumed that secure people openly process all attachment information, including negative ones. This unfavorable information is less disturbing for people with secure attachments than for people with insecure attachments. After receiving negative attachment information, a secure person believes that their attachment figure is safe and still trustworthy. In addition, they feel uncomfortable when exposed to negative attachment information and they develop adaptive adjustment skills to cope with distress due to past interactions with their attachment figure (Vandevivere, Braet, Bosmans, Mueller \& De Raedt, 2014).

A probabilistic understanding of threat might explain the difference between secure and insecure children in a neutral situation. Risk identification is substantial for sufficient recognition of an imminent threat (e.g. in social interactions) and to correctly identify threatening situations (Bockers, Roepke, Michael, Renneberg \& Knaevelsrud, 2014). Messman-Moore \& Brown (2006) explained the ability to quickly identify the threat as a result of sensitization to a threatening cue. This sensitization may serve as a buffer, which may call other cognitive processes, like interpretation bias into action.

\section{Conclusion}

The general principle of sexual selection can explain the significant difference between boys' and girls' response time in the secure attachment group. This principle shows that sex-related selections related to the importance of gender differences in childhood may continue to attachment styles (Del Giudice, 2015). Perhaps the faster response time in boys with a secure attachment can be seen as an adaptive response to the process of mating that extends throughout childhood and to extend attachment styles.

There are some limitations needed to be particularly attended to besides the interpretation of the findings of this study. The sample of this study was balanced but not big. Future studies may need a larger sample to investigate inter-individual differences in emotion recognition. In addition, the order of presentation could not be counterbalanced due to the design of the study, and it was the same for all subjects.

This study has several implications. This study highlights the significance of secure attachment in the early stages of life. Unpredictable factors could influence attachment patterns. Also, situational modulators may have different impacts on boys and girls, and it might be dependent on the developmental stage of the children. These factors have an impact on decision-making in the clinical setting for intervention design for children and school programming. Follow-up research can lead us to better programs that improve emotion regulation and communication strategies in children of different ages.

\section{Ethical Considerations}

\section{Compliance with ethical guidelines}

Written informed consent was obtained from the parents and active informed consent was obtained from the children. The ethical committee of Shahid Beheshti University reviewed and approved the protocol of this study.

\section{Funding}

This research did not receive any specific grant from funding agencies in the public, commercial, or not-forprofit sectors.

\section{Authors' contributions}

All authors equally contributed to preparing this article.

\section{Conflict of interest}

The authors declared no conflict of interest. 


\section{Acknowledgments}

We would like to thank Dr Mohsen Dehghani for his contribution in the design of this study.

\section{References}

Achenbach, T. M. (2001). Child behavior checklist. Burlingtone, 10, 1-9. [DOI: 10.1007/978-0-387-79948-3_1529]

Bockers, E., Roepke, S., Michael, L., Renneberg, B., \& Knaevelsrud, C. (2014). Risk recognition, attachment anxiety, self-efficacy, and state dissociation predict revictimization. PLoS One, 9(9), e108206. [DOI:10.1371/journal.pone.0108206] [PMID] [PMCID]

Bowlby, J. (1980). Attachment and loss. New York, NY: Basic Books.

Brenning, K., Soenens, B., Braet, C., \& Bosmans, G. (2011). The role of depressogenic personality and attachment in the intergenerational similarity of depressive symptoms: A study with early adolescents and their mothers. Personality and Social Psychology Bulletin, 37(2), 284-97. [DOI:10.1177/0146167210393533] [PMID]

Cassidy, J., \& Shaver, P. R. (2008). Handbook of attachment: Theory, research, and clinical applications ( $2^{\text {nd }} \mathrm{ed}$.). New York: The Guilford Press.

Dan, O., \& Raz, S. (2012). Adult attachment and emotional processing biases: An Event-Related Potentials (ERPs) study. Biological Psychology, 91(2), 212-20. [DOI:10.1016/j.biopsycho.2012.06.003] [PMID]

Dalrymple, K. A., Gomez, J., \& Duchaine, B. (2013). The Dartmouth Database of Children's Faces: Acquisition and validation of a new face stimulus set. PLoS One, 8(11), e79131. [DOI:10.1371/ journal.pone.0079131] [PMID] [PMCID]

de Montis, I. A., Brüne, M., Fresán, A., Ortega Font, V., Villanueva, J., Saracco, R., \& et al. (2013). Recognition of facial expression of the emotions and their relation to attachment styles and psychiatric symptoms: Preliminary study on psychiatric residents. Solud Mental, 36(2), 95-100. [DOI:10.17711/SM.01853325.2013.011]

Del Giudice, M. (2015). Attachment in middle childhood: An evolutionary-developmental perspective. New Directions for Child and Adilescent Development, 2015(148), 15-30. [DOI:10.1002/ cad.20101] [PMID]

Dewitte, M., \& De Houwer, J. (2008). Adult attachment and attention to positive and negative emotional face expressions. Journal of Research in Personality, 42(2), 498-505. [DOI:10.1016/j. jrp.2007.07.010]

Escobar, M. J., Rivera-Rei, A., Decety, J., Huepe, D., Cardona, J. F., Canales-Johnson, A., et al. (2013). Attachment patterns trigger differential neural signature of emotional processing in adolescents. PLoS One, 8(8), e70247. [DOI:10.1371/journal. pone.0070247] [PMID] [PMCID]

Fearon, R. P., Bakermans-Kranenburg, M. J., van IJzendoorn, M. H., Lapsley, A. M., \& Roisman, G. I. (2010). The significance of insecure attachment and disorganization in the development of children's externalizing behavior: A meta-analytic study. Child Development, 81(2), 435-56. [DOI:10.1111/j.14678624.2009.01405.x] [PMID]

Fraedrich, E. M., Lakatos, K., \& Spangler, G. (2010). Brain activity during emotion perception: The role of attachment representation. Attachment $\mathcal{E}$ Human Development, 12(3), 231-48. [DOI:10.1080/14616731003759724] [PMID]

Karayanidis, F., Kelly, M., Chapman, P., Mayes, A., \& Johnston, P. (2009). Facial identity and facial expression matching in 5-12-year-old children and adults. Infant and Child Development, 18(5), 404-21. [DOI:10.1002/icd.615]

Niedenthal, P. M., Brauer, M., Robin, L., \& Innes-Ker, Å. H. (2002). Adult attachment and the perception of facial expression of emotion. Journal of Personality and Social Psychology, 82(3), 419-33. https:// doi.org/10.1037/0022-3514.82.3.419

Messman-Moore, T. L., \& Brown, A. L. (2006). Risk perception, rape, and sexual revictimization: A prospective study of college women. Psychology of Women Quarterly, 30(2), 159-72. [DOI:10.1111/j.1471-6402.2006.00279.x]

Minaei, A. (2006). [Adaptation and standardization of child behavior checklist, youth self-report, and teacher's report forms (Persian)]. Journal of Exceptional Children (Research on Exceptional Children), 6(19), 529-58. http://joec.ir/article-1-416-fa. htm

Minagawa-Kawai, Y., Matsuoka, S., Dan, I., Naoi, N., Nakamura, K., \& Kojima, Sh. (2008). Prefrontal activation associated with social attachment: Facial-emotion recognition in mothers and infants. Cerebral Cortex, 19(2), 284-92. [DOI:10.1093/ cercor/bhn081] [PMID]

Murray, L., Arteche, A., Fearon, P., Halligan, S., Goodyer, I., \& Cooper, P. (2011). Maternal postnatal depression and the development of depression in offspring up to 16 years of age. Journal of the American Academy of Child \& Adolescent Psychiatry, 50(5), 460-70. [DOI:10.1016/j.jaac.2011.02.001] [PMID]

Ontai, L. L. \& Thompson, R. A. (2002). Patterns of attachment and maternal discourse effects on children's emotion understanding from 3 to 5 years of age. Social Development, 11(4), 433-50. [DOI:10.1111/1467-9507.00209]

Petrowski, K., Schurig, S., Schmutzer, G., Brähler, E., \& StöbelRichter, Y. (2015). Is it attachment style or socio-demography: Singlehood in a representative sample. Frontiers in Psychology 6, 1738. [DOI:10.3389/fpsyg.2015.01738] [PMID] [PMCID]

Pons, F., Harris, P. L., \& de Rosnay, M. (2004). Emotion comprehension between 3 and 11 years: Developmental periods and hierarchical organization. European Journal of Developmental Psychology, 1(2), 127-52. [DOI:10.1080/17405620344000022]

Emde, D. P., \& Wolf, D. (2003). Revealing the inner worlds of young children: The macarthur story stem battery and parent-child narratives. New York: Oxford University Press.

Ronaghi, S., Delavar, A., \& Mazaheri, M. A. (2012). [Development, validation and normalization of the "middle childhood attachment scale" (Persian)]. Journal of Behavioral Sciences, 4(12), 35-49. https://www.sid.ir/fa/journal/ViewPaper. aspx?ID=224191

Shaver, P. R., \& Mikulincer, M. (2002). Attachment-related-sychodynamics. Attachment \& Human Development, 4(2), 133-61. [DOI:10.1080/14616730210154171] [PMID] 
Schneider, B. H., Atkinson, L., \& Tardif, C. (2001). Child-parent attachment and children's peer relations: A quantitative review. Developmental Psychology, 37(1), 86-100. [DOI:10.1037/0012-1649.37.1.86] [PMID]

Spangler, G., Maier, U., Geserick, B., \& von Wahlert, A. (2010). The influence of attachment representation on parental perception and interpretation of infant emotions: A multilevel approach. Developmental Psychobiology, 52(5), 411-23. [DOI:10.1002/dev.20441] [PMID]

Spruyt, A., Clarysse, J., Vansteenwegen, D., Baeyens, F., \& Hermans, D. (2010). Affect 4.0: A free software package for implementing psychological and psychophysiological experiments. Experimental Psychology, 57(1), 36-45. [DOI:10.1027/16183169/a000005] [PMID]

Steele, H., Steele, M., \& Croft, C. (2008). Early attachment predicts emotion recognition at 6 and 11 years old. Attachment $\mathcal{E}$ Human Development, 10(4), 379-93. [DOI:10.1080/14616730802461409] [PMID]

Turner, P. J. (1991). Relations between attachment, gender, and behavior with peers in preschool. Child Development, 62(6), 1475-88. [DOI:10.2307/1130820] [PMID]

Tomkins, S. S. (1991). Affect, imagery, consciousness, Vol. 3. The negative affects: Anger and fear. New York: Springer Publishing Company.

Vandevivere, E., Braet, C., Bosmans, G., Mueller, S. C., \& De Raedt, R. (2014). Attachment and children's biased attentional processing: Evidence for the exclusion of attachment-related information. PLoS One, 9(7), e103476. [DOI:10.1371/journal. pone.0103476] [PMID] [PMCID]

Wechsler, D. (1974). Wechsler intelligence scale for children - revised. New York: Psychological Corporation. 